\title{
Respiratory and sleep disorders in mucopolysaccharidosis
}

\author{
Kenneth I. Berger • Simone C. Fagondes • \\ Roberto Giugliani • Karen A. Hardy • Kuo Sheng Lee • \\ Ciarán McArdle • Maurizio Scarpa • Martin J. Tobin • \\ Susan A. Ward • David M. Rapoport
}

Received: 31 August 2012 /Revised: 12 October 2012 / Accepted: 15 October 2012 /Published online: 15 November 2012

(C) The Author(s) 2012. This article is published with open access at Springerlink.com

\begin{abstract}
MPS encompasses a group of rare lysosomal storage disorders that are associated with the accumulation of glycosaminoglycans (GAG) in organs and tissues. This accumulation can lead to the progressive development of a variety of clinical manifestations. Ear, nose, throat (ENT) and
\end{abstract}

\section{Communicated by: Ed Wraith}

Details of the contributions of individual authors All authors have contributed to the content of the manuscript and revised it critically for important intellectual content.

Electronic supplementary material The online version of this article (doi:10.1007/s10545-012-9555-1) contains supplementary material, which is available to authorized users.

\section{K. I. Berger}

Department Medicine, Physiology and Neuroscience, André

Cournand Pulmonary Physiology Laboratory, Bellevue Hospital,

New York University School of Medicine,

New York, NY, USA

\section{S. C. Fagondes}

Department Pulmonary Medicine,

Hospital de Clinicas de Porto Alegre,

Porto Alegre, Brazil

R. Giugliani

Department Genetics/UFRGS,

Medical Genetics Service/HCPA and INAGEMP,

Porto Alegre, Brazil

\section{K. A. Hardy}

Children's Hospital \& Research Center Oakland,

Oakland, CA, USA

\section{K. S. Lee}

Mackay Memorial Hospital,

Taipei, Taiwan

\section{McArdle}

Birmingham Childrens Hospital,

Birmingham, UK respiratory problems are very common in patients with MPS and are often among the first symptoms to appear. Typical features of MPS include upper and lower airway obstruction and restrictive pulmonary disease, which can lead to chronic rhinosinusitis or chronic ear infections, recurrent upper and

\section{Scarpa}

Department Pediatrics, University of Padua,

Padua, Italy

M. J. Tobin

Hines VA Hospital,

Hines, IL, USA

\section{S. A. Ward}

Human Bio-Energetics Research Centre,

Crickhowell, UK

\section{M. Rapoport}

Department of Medicine,

New York University School of Medicine,

New York, NY, USA

\section{K. I. Berger $(\bowtie)$}

Department of Medicine, Physiology and Neuroscience,

New York University School of Medicine,

550 First Ave, Room RR108,

New York, NY 10016, USA

e-mail: Kenneth.Berger@nyumc.org 
lower respiratory tract infections, obstructive sleep apnoea, impaired exercise tolerance, and respiratory failure. This review provides a detailed overview of the ENT and respiratory manifestations that can occur in patients with MPS and discusses the issues related to their evaluation and management.

\section{MPS disease overview}

The mucopolysaccharidoses (MPS) are rare inherited metabolic diseases associated with deficiencies in enzymes involved in the degradation of glycosaminoglycans (GAG) (Muenzer 2011). Progressive accumulation of GAG in multiple tissues and organs (Table 1) lead to an array of manifestations that worsen with age, ultimately resulting in severe morbidity and premature death (Muenzer 2011). Most patients share a typical appearance characterized by coarsened facial features, reduced height, and skeletal abnormalities. Other manifestations include impaired vision and hearing, hepatosplenomegaly, cardiovascular disease, spinal cord compression, and ear-nose-throat (ENT) and respiratory problems. Cognitive impairment is the main feature in MPS III and may occur in MPS I, II and VII. Although many similarities exist, the spectrum and severity of disease manifestations vary between and within the different MPS types.

This review addresses ENT and respiratory disorders occurring in MPS, and discusses their evaluation and management.

\section{Physiology of respiration and impact of sleep}

Respiration results from the interaction of pathways under cerebral control. The brain controls the synchronous movement of the diaphragm, ribs and abdomen; modulating influences are exerted by feedback from arterial blood gas tensions, $\mathrm{pH}$ and pulmonary-mechanical factors. The brain also controls phasic coordination of upper airway (UA) muscles, which interact with anatomic factors to determine the UA resistance. Coordinated activity of the chest wall and UA muscles is required to achieve normal ventilation.
Changes in UA and diaphragmatic control occur with sleep onset, and can thus disrupt ventilation.

\section{ENT and respiratory disorders in MPS}

Respiratory disorders occur in all MPS types (John et al 2011; Leighton et al 2001; Lin et al 2010; Muhlebach et al 2011; Nashed et al 2009; Santamaria et al 2007; Semenza and Pyeritz 1988) (Table 2). However, due to low patient numbers no conclusions can be made regarding the prevalence and severity of these problems in each MPS type. The ENT and respiratory disorders can be divided into airway abnormalities, alterations in respiratory mechanics, and effects of sleep (Fig. 1 and Table 3).

\section{Airway abnormalities}

Supraglottic manifestations are common in MPS and develop due to cranial and spinal abnormalities (e.g., flattened nasal bridge, short neck, high epiglottis, mandibular abnormalities, abnormal cervical vertebrae) and GAG deposition in the mouth, nose and throat (Leboulanger et al 2011; Leighton et al 2001; Myer 1991; Shih et al 2002). Oral manifestations include gingival hyperplasia, mucosal oedema, mucoid secretions, and impaired opening of the mouth. Chronic rhinosinusitis and chronic otitis media may occur and produce hearing impairment (John et al 2011; Muhlebach et al 2011), and the rhinosinusitis can contribute to UA obstruction during sleep.

GAG storage can also cause distension of the tongue, adenoids and/or tonsils with formation of collapsible, spaceoccupying lesions in pharyngolaryngeal walls (Simmons et al 2005). In extreme cases, excessive tissue at the arytenoid cartilages and aryepiglottic folds can prolapse into the laryngeal inlet causing stridor and airway compromise (Simmons et al 2005). Obstruction is often worsened by presence of thickened secretions throughout the upper and lower respiratory tracts (Leighton et al 2001). ENT manifestations are among the first disease-specific manifestations to appear, may trigger diagnosis of MPS (Muhlebach et al 2011; Wold et al 2010), and tend to progress with age.
Table 1 Overview of types of mucopolysaccharidosis (MPS) and glycosaminoglycans that accumulate in each of these MPS types

\begin{tabular}{llllll}
\hline MPS & & $\begin{array}{l}\text { Dermatan } \\
\text { sulfate (DS) }\end{array}$ & $\begin{array}{l}\text { Heparan } \\
\text { sulfate (HS) }\end{array}$ & $\begin{array}{l}\text { Keratan } \\
\text { sulfate (KS) }\end{array}$ & $\begin{array}{l}\text { Chondroitin } \\
\text { sulfate (CS) }\end{array}$ \\
\hline I (H, HS, S) & Hurler, Hurler-Scheie, Scheie & + & + & \\
II & Hunter & + & + & & + \\
III & Sanfilippo & & + & + & + \\
IVa & Morquio & & & + \\
IVb & & & & + \\
VI & Maroteaux-Lamy & + & & + \\
VII & Sly & + & + & + \\
\hline
\end{tabular}


Table 2 Key respiratory manifestations in the different mucopolysaccharidosis (MPS) types. Adapted from Muhlebach et al 2011, with permission from Elsevier Ltd

\begin{tabular}{llll}
\hline MPS & $\begin{array}{l}\text { Upper airway } \\
\text { obstruction }\end{array}$ & $\begin{array}{l}\text { Lower airway } \\
\text { obstruction }\end{array}$ & $\begin{array}{l}\text { Restrictive } \\
\text { lung disease }\end{array}$ \\
\hline I & +++ & +++ & +++ \\
II & +++ & +++ & ++ \\
III & Minimal & Minimal & Minimal \\
IV & ++ & + & +++ \\
VI & +++ & +++ & ++ \\
VII & +++ & +++ & ++ \\
\hline
\end{tabular}

Airway abnormalities and airway collapse may also occur in infraglottic airways, including the trachea and central airways. Tracheobronchomalacia may develop secondary to GAG deposition in the tracheobronchial cartilage (Nagano et al 2007; Pelley et al 2007; Shih et al 2002; Sims and Kempiners 2007). Alternatively, tracheal collapse can occur due to decreased tracheal traction from decreased lung volume (Heinzer et al 2005), although this has not been specifically shown in MPS. MPS IV patients may develop airway occlusion upon neck flexion. These patients assume a "sniff position" (extension of the neck to increase airway patency) during wakefulness and may sleep in the prone position. Clinical manifestations include dyspnoea, difficulty clearing secretions, cough, wheezing, and recurrent bronchitis or pneumonia (John et al 2011; Leighton et al 2001; Muhlebach et al 2011; Murgu and Colt 2006; Pelley et al 2007). Another study also suggested alveolar and interstitial pulmonary involvement by GAG deposition (Semenza and Pyeritz 1988). Airway obstruction and parenchymal abnormality have potential to impair pulmonary $\mathrm{O}_{2}$ uptake and $\mathrm{CO}_{2}$ excretion.
Alteration in respiratory mechanics

Multiple abnormalities in MPS patients can reduce ventilatory capacity, manifesting as reduction in vital capacity (VC). Kyphoscoliosis and pectus carinatum are common and alter chest wall shape and structure. Diaphragm excursion may be compromised by liver and spleen enlargement (Buhain et al 1975; Giugliani et al 2007; Leighton et al 2001). Diaphragmatic weakness may result from spinal cord compression above the phrenic nerve origin (C3-C5), but there is currently no evidence for this hypothesis.

Pulmonary function can also be affected by the characteristic short stature and skeletal dysplasia. In MPS disorders associated with short stature (e.g., MPS VI), patient height is the primary determinant of VC and improved pulmonary function during enzyme replacement therapy (ERT) is frequently associated with growth and increased stature (Swiedler et al 2005; Harmatz et al 2010).

The combined effect of these alterations in respiratory mechanics coupled with airway abnormalities may lead to respiratory failure.

\section{Effects of sleep}

Ventilatory compromise is exacerbated by normal sleep mechanisms that increase UA collapsibility, thus magnifying any impairment to generation of inspiratory effort. The effects of sleep are particularly evident during REM sleep, which causes loss of tone in accessory muscles of respiration and reduction in ventilatory $\mathrm{CO}_{2}$ chemosensitivity (Dempsey et al 2010). Due to the changes that occur with sleep onset, ventilatory compromise often first manifests as sleep disordered breathing (SDB) and unexplained hypoxemia during sleep.
Fig. 1 Mechanisms that predispose to sleep disordered breathing in patients with mucopolysaccharidosis (MPS)

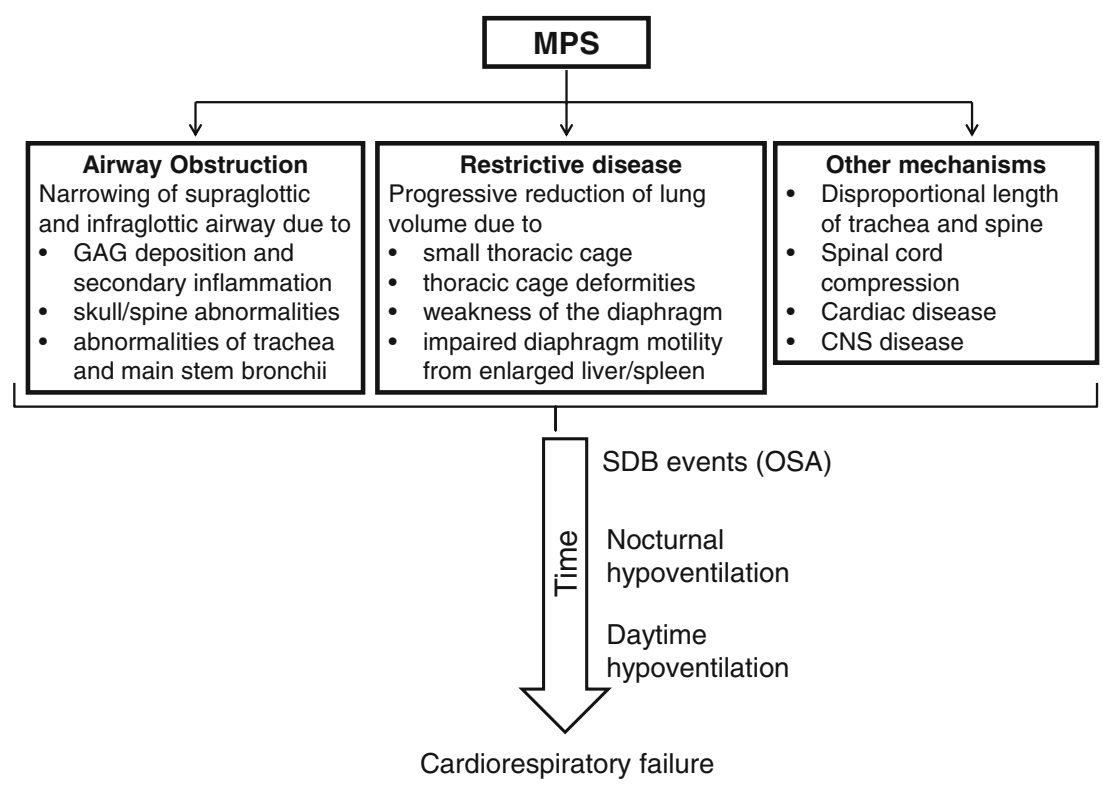


Table 3 Manifestations of mucopolysaccharidosis (MPS) that may affect respiratory function and their prevalence in a study including 21 patients with MPS I, II, IV, VI, and VII. Adapted from Semenza et al (Semenza and Pyeritz 1988), with permission from Williams \& Wilkins

$\%$ of patients $(N=21)$

\begin{tabular}{ll} 
Airway narrowing & \\
Hypertrophy of tonsils/adenoids & 67 \\
Macroglossia & 57 \\
Nasopharyngeal obstruction & 86 \\
Supraglottic narrowing & 92 \\
Infraglottic narrowing & 62 \\
Pulmonary disease & \\
Obstructive defect & 71 \\
Focal atelectasis & 35 \\
Recurrent pneumonia & 40 \\
Interstitial markings & 24 \\
Arterial hypoxemia awake & 57 \\
Arterial hypoxemia asleep & 10 \\
Sleep apnoea & \\
Central & 0 \\
Obstructive & 89 \\
Thoracolumbar spine deformity & 67 \\
Scoliosis & 67 \\
Thoracic hyperkyphosis & 62 \\
Lumbar hyperlordosis & 38 \\
Thoracolumbar gibbus & 57 \\
Cervical spine involvement & \\
Cervical spine subluxation & 63 \\
Odontoid hypoplasia & \\
Cord compression & \\
\hline &
\end{tabular}

SDB occurs in $>80 \%$ of MPS patients (John et al 2011; Leighton et al 2001; Semenza and Pyeritz 1988). It can be categorized as either obstructive sleep apnoea (OSA) or sustained hypoventilation. OSA occurs from an interaction between abnormalities of the skull and GAG deposition in the UA and perhaps from remote effects of thoracic deformation causing reduced lung volumes. OSA can lead to daytime sleepiness and long-term cardiovascular sequellae and often presents as loud and disruptive snoring. Sleep studies demonstrate recurrent short episodes $(<90 \mathrm{~s})$ of either reduced or absent ventilation due to UA obstruction. In more advanced stages, compensation for $\mathrm{CO}_{2}$ retention during individual SDB events may be impaired by reduction of $\mathrm{VC}$ and inability to increase ventilation during inter-event intervals (Fig. 2) (Berger et al 2000). These patients exhibit progressive $\mathrm{CO}_{2}$ retention throughout the night, i.e., nocturnal hypoventilation (Mellies et al 2003; Ragette et al 2002).

A restrictive abnormality and/or diaphragmatic weakness may also cause sustained periods of hypoventilation. Sleep studies demonstrate prolonged periods (several minutes) of arterial $\mathrm{O}_{2}$ desaturation consequent to hypoventilation (Leighton et al 2001). Reduced VC, which is influenced by respiratory muscle strength, may be a good predictor of SDB severity (Ragette et al 2002). Whereas patients with $\mathrm{VC}<60 \%$ of predicted have a predisposition to SDB, those with a VC $<40 \%$ of predicted are prone to sustained hypoventilation and $\mathrm{CO}_{2}$ retention.

If improperly managed, nocturnal hypoventilation may lead to pulmonary hypertension, cor pulmonale and eventually respiratory failure (John et al 2011; Semenza and Pyeritz 1988), a common cause of death in MPS (Leighton et al 2001).

Other potential mechanisms

Tracheal distortion is characteristic for MPS and may reflect disproportionate length of the trachea relative to the shortened spinal length (Walker et al 2003). In combination with laxity of tracheal tissue, it can cause airway collapse (Walker et al 2003). Cervical or lumbar spinal cord lesions may weaken expiratory muscles, impair cough and reduce secretion clearance, predisposing patients to recurrent pneumonia. In patients with cardiac abnormalities or chronic respiratory failure, nocturnal shift in leg fluid volume may cause UA oedema. Furthermore, the respiratory arousal threshold (i.e., the ease with which an individual wakes up in response to respiratory stimuli) may be modified due to brain modifications. However, these issues remain to be investigated.

\section{Assessment of respiratory function in MPS patients}

\section{Evaluation of UA anatomy}

Classification systems for grading mouth and UA abnormalities in MPS include a modified Mallampati classification system based on visibility of the tonsils, pillars, uvula and soft palate and a classification system for grading tonsillar hypertrophy (Friedman et al 1999). Computed tomography (CT) of retropalatal and retroglossal spaces can demonstrate reduction in UA volume in MPS patients (Santamaria et al 2007). Multi-detector CT imaging can also evaluate airway size, airway structure and the lung parenchyma (Ingelmo et al 2011) (Fig. 3i and j).

Dynamic changes in the airway during respiration can be evaluated using flexible endoscopy (Fig. 3a, b, c, d, e, f, g and h). Fiberoptic examination is preferably done in a sitting position, which requires less ventilatory support than the supine position. Pharyngeal and laryngeal abnormalities can be classified based on the level of mucosal alteration (personal communication Dr. A. Keilmann). Grading systems based on adenoid hypertrophy and obstruction of the choanal opening and tubal ostium exist to evaluate nasal cavity obstruction (Cassano et al 2003; Josephson et al 2011; Parikh et al 2006). 
Fig. 2 Impaired compensation for sleep disordered breathing, leading to hypoventilation during sleep. Reproduced from Berger et al (Berger et al 2000), with permission from the American Physiology Society
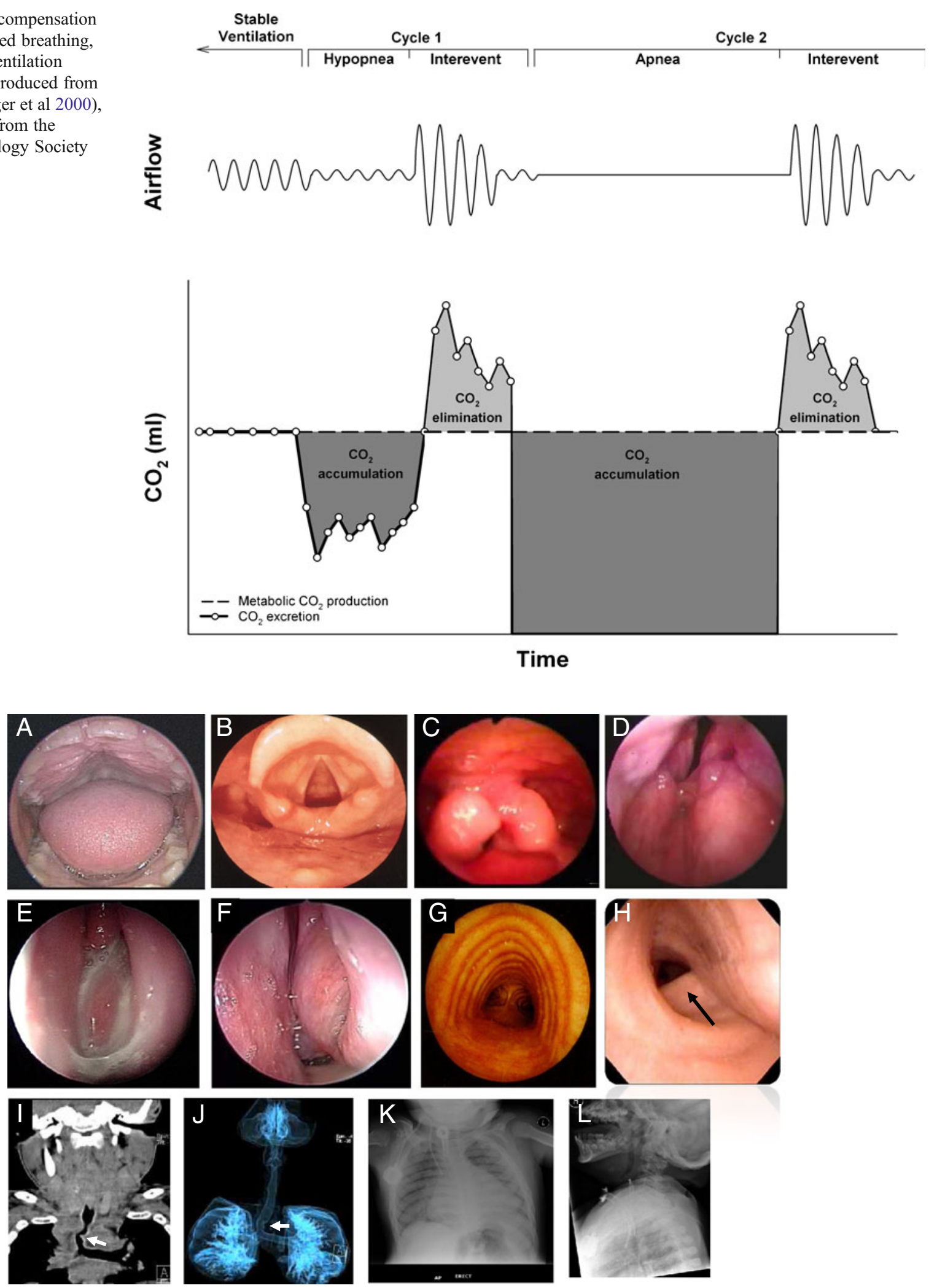

Fig. 3 a Oropharyngeal image from a patient with mucopolysaccharidosis (MPS) II showing macroglossia and gingival hyperplasia; b normal lyaryngoscopic image; c-d laryngoscopic images from a patient with MPS II showing a thick laryngeal wall, tonsillar hyperplasia, and redundant arytenoid mucosa prolapse into laryngeal inlet; e-f nasal endoscopic images showing inflammation and abnormal mucous secretion in a patient with

MPS VI; $\mathbf{g}$ normal bronchoscopic image (Canani et al 2003); $\mathbf{h}$-j bronchoscopic image and CT scans from a patient with MPS IV showing tracheal deformity and narrowing; k-I typical frontal and lateral plain X-rays of the chest of a child with MPS II showing skeletal abnormalities and the presence of a tracheostomy and possibly infective changes in the lungs (hazy shadow in the right lower zone of the frontal image) 
Plain roentgenograms of the chest, spine and soft tissue of the neck may demonstrate airway obstruction, atelectasis, skeletal changes that cause restrictive disease and/or spinal cord compression (Fig. 3k and 1). Magnetic resonance imaging may provide information on skeletal changes, but has limited utility for evaluating lung parenchyma. Imaging MPS patients can be challenging. Sedation may be required for young or uncooperative patients, although complications may occur due to the high anaesthetic risk (Walker et al 2012).

\section{Assessment of respiratory function}

Respiratory symptoms and hypoventilation may not be detected as many patients are inactive and since respiratory dysfunction is often poorly correlated with clinical appearance. Nevertheless, anticipation of respiratory problems and management at an early stage is important to maximize treatment outcome. Symptoms that require evaluation include progressive dyspnoea, reduced physical activity, exercise intolerance, wheezing or stridor, tachycardia and cyanosis.

Spirometry is the most frequent test utilized in MPS to assess the $\mathrm{VC}$ and the forced expiratory volume in $1 \mathrm{~s}$ $\left(\mathrm{FEV}_{1}\right)$. Reduction in $\mathrm{VC}$ is suggestive of a restrictive abnormality while reduction in $\mathrm{FEV}_{1}$ (expressed as $\mathrm{FEV}_{1}$ / VC) indicates airflow obstruction. Reduction in VC can reflect changes in lung compliance, chest wall compliance, and/or neuromuscular weakness. Reduced VC may also result from air trapping. Standard normal values for spirometry cannot be applied in MPS patients due to the diseaseinduced growth impairment and expressing $\mathrm{VC}$ as a \% of normal is of limited value (Swiedler et al 2005). In addition, spirometry may not be possible in children who are too young to cooperate $(<5$ years $)$ and in patients with cognitive impairment. Despite its limitations, spirometry remains a valid clinical tool since all respiratory abnormalities that occur in MPS produce a decrease in VC. Spirometry has been commonly used for screening, to determine longitudinal disease progression and assess response to therapy.

Maximum voluntary ventilation (MVV) can be assessed as an alternative to spirometry. However, this test is physically demanding and can be difficult for MPS patients. Promising alternatives to assess for airflow obstruction include multiple breath inert gas washout and impulse oscillometry. These tests are performed during tidal breathing and may detect early airway disease (Aurora et al 2005; Oppenheimer et al 2007; Pasker et al 1996; Klug and Bisgaard 1996; Hellinckx et al 1998).

The degree of pulmonary restriction or hyperinflation can be measured using plethysmograhy, helium dilution or nitrogen washout. The diagnosis and management of parenchymal disease requires measurement of diffusion. This measurement is only reliable if the minimum volume inspired is $1.2 \mathrm{~L}$ and may not be possible in MPS patients with reduced lung capacity.
Respiratory failure

Respiratory failure occurs from an imbalance between ventilation and metabolic rate. It can be identified by presence of hypercapnia on analysis of arterial blood gases. Since arterial blood gas analysis may not be available in the outpatient clinic, serum bicarbonate $\left(\mathrm{HCO}_{3}{ }^{-}\right)$concentration serves as a screening test since elevated values may indicate renal compensation for respiratory acidosis. If the serum $\left[\mathrm{HCO}_{3}{ }^{-}\right]$is $\geq 28 \mathrm{mEq} / \mathrm{L}$, respiratory failure should be suspected and assessment of arterial blood gases should be considered (Mokhlesi et al 2007).

Sleep studies

Sleep studies/polysomnograpy are used to diagnose and determine severity of respiratory sleep disorders. Since the incidence of SDB is high in MPS, polysomnography should be performed in all patients after diagnosis. Studies can be repeated based on presence of snoring, excessive daytime somnolence, development of respiratory failure and reduction in VC. Typical findings include recurrent OSA, tachycardia, decrease in arterial $\mathrm{O}_{2}$ saturation and recurrent arousal (Kamin 2008). It is important to distinguish OSA from sustained hypoventilation as these require different treatment approaches. Sustained nocturnal hypoventilation is suggested by oxygen desaturation in absence of OSA and can be confirmed by an increase in $\mathrm{PCO}_{2}$ during sleep, but this often carries over into wakefulness.

\section{Exercise tolerance testing}

Exercise intolerance in MPS patients is generally measured using timed stair climbing or walk tests (e.g., 6- and 12-min walk tests [MWT]) (Harmatz et al 2008; Muenzer et al 2006; Wraith et al 2004). The 6-MWT is a practical test of submaximal functional capacity which mimics daily activities (e.g., American Thoracic Society 2002). Timed walk tests are used to assess functional status, monitor disease progression and response to interventions. The distance walked is generally the only variable that is evaluated. Valuable additional information could be obtained by measuring resting and end-exercise heart rate and arterial $\mathrm{O}_{2}$ saturation (e.g., American Thoracic Society 2002). Reference values for the 6-MWT exist (Enright and Sherrill 1998; Li et al 2007); however, applicability in MPS is unclear due to the associated cognitive and physical impediment.

Although not currently used, cardiopulmonary exercise testing might be valuable because of its wider diagnostic scope in terms of respiratory, cardio-circulatory and musclemetabolic function (American Thoracic Society/American College of Chest Physicians 2003; Wasserman et al 2012). The symptom-limited ramp test provides a gradational stress spanning the entire tolerance range, with breath-by-breath 
measurement of ventilatory, gas-exchange and cardiovascular variables providing the substrate for analysing the causes of exercise intolerance, based on profiles of physiological system function.

\section{Management of airway problems in MPS}

\section{Airway management}

UA collapse at the pharyngeal and laryngeal level may occur due to rhinitis or adenoidal obstruction. Treatments may include nasal decongestions to control excessive mucus production, and steroids to reduce swelling. Adenoidectomy and/or tonsillectomy are also often required, and frequently performed before diagnosis of MPS. The procedure can be dangerous as surgeons may not anticipate potential anaesthetic and surgical complications and procedures should be performed by experienced personnel (Walker et al 2012; Simmons et al 2005). The operative field is frequently limited by thick and hard oropharyngeal tissue and UA scar tissue that may compromise the already small airway (Yeung et al 2009). In advanced cases, andenotonsillectomy can be inadequate or impossible. Moreover, any improvements achieved may be temporary because of progressive involvement of the oropharynx and trachea (Kamin 2008; Muhlebach et al 2011).

Patients with lower airway obstruction may use inhaled steroids to decrease airway inflammation. Because of instability of the tracheal and bronchial wall, patients may respond better to an anticholinergic bronchodilator agent than to a beta-agonist (Muhlebach et al 2011).

\section{SDB}

The presence of SDB should prompt evaluation of the UA. Removal of tonsils and adenoids, if enlarged, may alleviate UA obstruction. SDB can also be managed by application of continuous positive airways pressure (CPAP), which delivers air at an elevated pressure using a mask that fits around the nose $+/-$ mouth (Sullivan et al 1981; Rapoport et al 1982; Ginzburg et al 1990). The pressure acts as a dynamic stent and prevents airway collapse during inspiration. Nocturnal hypoventilation should be suspected if arterial $\mathrm{O}_{2}$ desaturation persists with CPAP or occurs in the absence of OSA (Berger et al 2001). In this case, non-invasive ventilator support systems (e.g., bilevel positive airway pressure) can be utilized and a backup respiratory rate can be added to prevent sustained hypoventilation. (Muhlebach et al 2011). Assisted ventilation may provide respiratory muscle rest and improve sleep quality, relieve nocturnal dyspnoea and lead to normalization of daytime blood gases. Supplemental $\mathrm{O}_{2}$ can be added if arterial $\mathrm{O}_{2}$ desaturation persists but should be used with caution as it may suppress ventilatory and arousal drives. Careful titration of the rate of $\mathrm{O}_{2}$ administration and monitoring of arterial $\mathrm{CO}_{2}$ levels are required to prevent $\mathrm{O}_{2}$-induced hypercapnia.

As compliance with CPAP and non-invasive ventilation is often low in MPS, compliance monitoring is imperative. In addition, leaks due to poor-fitting masks reduce treatment efficacy (Kamin 2008; Muhlebach et al 2011). Patients who adopt a sniff position may require specialized attention to ensure comfortable and adequate therapy. If properly used, CPAP and bilevel devices will improve breathing during sleep and provide relief of daytime somnolence and other consequences of SDB.

Tracheostomy may be required either when CPAP or noninvasive ventilation is ineffective or tracheomalacia and UA obstruction are present during wakefulness (Muhlebach et al 2011; Wold et al 2010). However, placement of the tracheostomy tube can be difficult and may be associated with stomal narrowing, granulation formation, infrastomal tracheal stenosis, wound infection, and tracheomalacia (Jeong et al 2006; Muhlebach et al 2011; Pelley et al 2007; Sims and Kempiners 2007). Problems may persist due to persistent airway collapse distal to the tip of the endotracheal tube (Pelley et al 2007) and patient preference for sleeping in the prone position. When the above therapies are ineffective, uncontrolled respiratory failure with cor pulmonale may develop and death may occur.

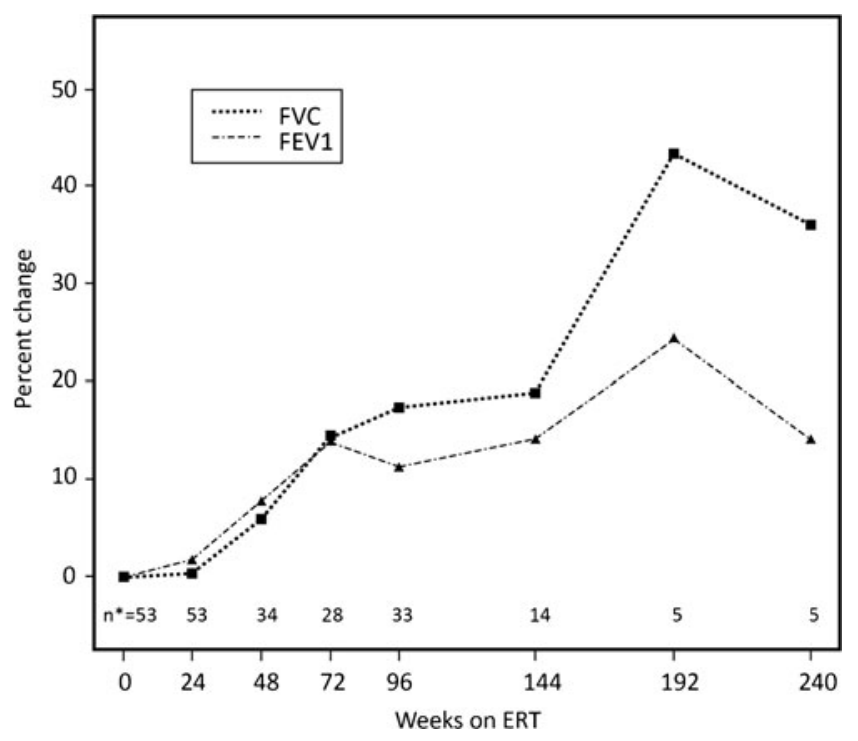

Fig. 4 Changes from baseline in forced vital capacity (FVC) and forced expiratory volume in $1 \mathrm{~s}\left(\mathrm{FEV}_{1}\right)$ after initiation of enzyme replacement therapy (ERT). Results from a long-term extension study in patients with mucopolysaccharidosis VI (Harmatz et al 2010), reproduced with permission. $n^{*}$ : number of patients for whom data were available for that particular time point 
Supportive therapies

Multiple supportive therapies are required to maintain optimal functional status. All patients should receive regular vaccinations, including pneumococcus and influenza vaccinations. Treatment of respiratory tract infections should be early and aggressive. Impairment in secretion clearance can be addressed by both manual and mechanical techniques. Inhaled bronchodilators can be used in conjunction with these airway clearance techniques. Bronchodilators and corticosteroids (inhaled and/or oral) may be useful if concurrent asthma is present. As restrictive pulmonary disease may be caused be spinal cord compression, pulmonary function may also improve after decompression surgery.

\section{Disease-targeting therapies}

ERT is available for and beneficial in patients with MPS I, II, and VI. A positive impact has been demonstrated on 6- or 12-MWT and on pulmonary function (Clarke et al 2009; Harmatz et al 2004, 2005, 2006; Muenzer et al 2011, 2006; Okuyama et al 2010; Wraith et al 2004).

An open-label extension study of ERT in MPS VI showed sustained improvement in walking distance for up to 240 weeks (Harmatz et al 2008). In addition, $\mathrm{FEV}_{1}$ and VC increased (11\% and $17 \%$, respectively) after 96 weeks of ERT with continued improvement thereafter (Fig. 4) (Harmatz et al 2010). Sustained improvement in MVV has also been demonstrated. These findings suggest that improved exercise tolerance in this population was related, at least partly, to improved pulmonary function.

The impact of ERT on pulmonary function should be interpreted in relationship to patient age. In younger children, increases in pulmonary function over time may (partly) be explained by growth. In line with this consideration, improvement in VC was only seen in patients with MPS II up to 18 years old (Muenzer et al 2011). In contrast, in MPS VI patients, (Harmatz et al 2010) increases in $\mathrm{VC}$ and $\mathrm{FEV}_{1}$ were observed in patients $>12$ years old despite minimal increases in height. In these patients, improvement in pulmonary function could only be explained by mechanisms other than growth, such as changes in bony structure, improvements in mobility, joint contractures or respiratory muscle function, shrinking of liver and spleen, or decreased GAG deposition in soft tissues. In adolescent patients, changes in pulmonary function may also be related to puberty.

Although haematopoietic stem cell transplantation (HSCT) is beneficial, and superior to ERT, for prevention of cognitive decline in young patients with MPS IH, effects in other MPS types tend to be poor (Rovelli 2008). Its use has been limited in the past by a high morbidity and mortality rate and the lack of matched donors, but this is changing with the increasing use of cord blood allowing a shorter interval between diagnosis and HSCT and a lower graft failure rate (Turbeville et al 2011; Prasad and Kurtzberg 2010). Most knowledge on the effect of HSCT on pulmonary function is based on case reports, some suggesting a positive impact (Krivit et al 1984; Wang et al 2008).

\section{Conclusions}

The high prevalence of ENT and respiratory manifestations in MPS patients, their severity, and their appearance early in the disease course dictate that evaluation and follow-up of these problems is extremely important. Since asymptomatic patients may have severely impaired pulmonary function, pulmonary disease may go undetected for years without appropriate screening. However, the measurement of pulmonary function in MPS patients remains an important challenge due to the complexity of the disease and a lack of data on "usual pulmonary function" in these patients. Nevertheless, longitudinal follow-up of absolute values can be useful for monitoring the evolution of respiratory disease in a single patient. Current management guidelines for MPS I and MPS VI therefore recommend pulmonary function testing at diagnosis and every 6-12 months thereafter (Giugliani et al 2007; Muenzer et al 2009).

This review has addressed the pathophysiological mechanisms underlying respiratory manifestations in the different types of MPS. In addition, opportunities for enhanced evaluation of pulmonary function in these patients were highlighted. More sophisticated evaluation should help determine the mechanisms underlying the impact of ERT on exercise tolerance, $\mathrm{VC}$, and $\mathrm{FEV}_{1}$.

Acknowledgments The authors are grateful to Ismar Healthcare NV for their assistance in writing of the manuscript, which was funded by BioMarin Pharmaceutical Inc.

Funding The preparation of this manuscript was supported by BioMarin Pharmaceutical Inc.

Competing interests Kenneth Berger has received consultancy fees and/or speaker honoraria from BioMarin and Genzyme. Simone C. Fagondes received a fee for a conference at the respiratory function and anaesthesia meeting supported by BioMarin 2012. Roberto Giugliani has received investigator fees, and/or travel grants, and/or speaker honoraria and/or consultancy fees from Actelion, Amicus, BioMarin, Genzyme and Shire. Kuo Sheng Lee received travel grants and speaker honorarium from BioMarin for attending a MPS conference. Karen Ann Hardy and Ciarán McArdle received honorarium and expenses from BioMarin for attending MPS meetings sponsored by BioMarin. Maurizio Scarpa received unrestricted research and travel grants from BioMarin, Actelion, Genzyme and Shire. Martin J. Tobin has received royalties on a book, "Principles and Practice of Mechanical Ventilation", published by McGraw-Hill, Inc, New York. Susan A. Ward has no conflicts of interest. David M. Rapoport has received consultancy 
fees and speaker honoraria from BioMarin and consultancy fees, speaker honoraria and patent royalties for nasal CPAP from Fisher \& Paykel Healthcare.

Open Access This article is distributed under the terms of the Creative Commons Attribution License which permits any use, distribution, and reproduction in any medium, provided the original author(s) and the source are credited.

\section{References}

American Thoracic Society (2002) ATS statement: guidelines for the six-minute walk test. Am J Respir Crit Care Med 166:111-117

American Thoracic Society/American College of Chest Physicians (2003) Statement on cardiopulmonary exercise testing. Am J Respir Crit Care Med 167(211-277):2003

Aurora P, Bush A, Gustafsson P et al (2005) Multiple-breath washout as a marker of lung disease in preschool children with cystic fibrosis. Am J Respir Crit Care Med 171:249-256

Berger KI, Ayappa I, Sorkin IB, Norman RG, Rapoport DM, Goldring $\mathrm{RM}$ (2000) $\mathrm{CO}_{2}$ homeostasis during periodic breathing in obstructive sleep apnea. J Appl Physiol 88:257-264

Berger KI, Ayappa I, Chatr-amontri B, Marfatia A et al (2001) Obesity hypoventilation syndrome as a spectrum of respiratory disturbances during sleep. Chest 120:1231-1238

Buhain WJ, Rammohan G, Berger HW (1975) Pulmonary function in Morquio's disease: a study of two siblings. Chest 68:41-45

Canani SE, John AB, Schwartz IV et al (2003) Manejo de apnéia do sono em um paciente com mucopolysaccharidose. Hypn J Clin Exp Sleep Res 3:40-41

Cassano P, Gelardi M, Cassano M, Fiorella ML, Fiorella R (2003) Adenoid tissue rhinopharyngeal obstruction grading based on fiberendoscopic findings: a novel approach to therapeutic management. Int J Pediatr Otorhinolaryngol 67:1303-1309

Clarke LA, Wraith JE, Beck M et al (2009) Long-term efficacy and safety of laronidase in the treatment of mucopolysaccharidosis I. Pediatrics 123:229-240

Dempsey JA, Veasey SC, Morgan BJ, O’Donnell CP (2010) Pathophysiology of sleep apnea. Physiol Rev 90:47-112

Enright PL, Sherrill DL (1998) Reference equations for the six-minute walk in healthy adults. Am J Respir Crit Care Med 158:1384-1387

Friedman M, Tanyeri H, La Rosa M et al (1999) Clinical predictors of obstructive sleep apnea. Laryngoscope 109:1901-1907

Ginzburg AS, Önal E, Aronson RM, Schild JA, Mafee MF, Lopata M (1990) Successful use of nasal-CPAP for obstructive sleep apnea in Hunter syndrome with diffuse airway involvement. Chest 97:1496-1498

Giugliani R, Harmatz P, Wraith JE (2007) Management guidelines for mucopolysaccharidosis VI. Pediatrics 120:405-418

Harmatz P, Whitley CB, Waber L et al (2004) Enzyme replacement therapy in mucopolysaccharidosis VI (Maroteaux-Lamy syndrome). J Pediatr 144:574-580

Harmatz P, Ketteridge D, Giugliani R et al (2005) Direct comparison of measures of endurance, mobility, and joint function during enzymereplacement therapy of mucopolysaccharidosis VI (MaroteauxLamy syndrome): results after 48 weeks in a phase 2 open-label clinical study of recombinant human $\mathrm{N}$-acetylgalactosamine 4sulfatase. Pediatrics 115:e681-e689

Harmatz P, Giugliani R, Schwartz I et al (2006) Enzyme replacement therapy for mucopolysaccharidosis VI: a phase 3, randomized, double-blind, placebo-controlled, multinational study of recombinant human $\mathrm{N}$-acetylgalactosamine 4-sulfatase (recombinant human arylsulfatase B or rhASB) and follow-on, open-label extension study. J Pediatr 148:533-539

Harmatz P, Giugliani R, Schwartz IVD et al (2008) Long-term followup of endurance and safety outcomes during enzyme replacement therapy for mucopolysaccharidosis VI: final results of three clinical studies of recombinant human $\mathrm{N}$-acetylgalactosamine 4sulfatase. Mol Genet Metab 94:469-475

Harmatz P, Yu ZF, Giugliani R et al (2010) Enzyme replacement therapy for mucopolysaccharidosis VI: evaluation of long-term pulmonary function in patients treated with recombinant human $\mathrm{N}$-acetylgalactosamine 4-sulfatase. J Inherit Metab Dis 33:51-60

Heinzer RC, Stanchina ML, Malhotra A et al (2005) Lung volume and continuous positive airway pressure requirements in obstructive sleep apnea. Am J Respir Crit Care Med 172:114-117

Hellinckx J, De Boeck K, Bande-Knops J, van der Poel M et al (1998) Bronchodilator response in 3-6.5 years old healthy and stable asthmatic children. Eur Respir J 12:438-443

Ingelmo PM, Parini R, Grimaldi M et al (2011) Multidetector computed tomography (MDCT) for preoperative airway assessment in children with mucopolysaccharidoses. Minerva Anestesiol 77:774-780

Jeong HS, Cho DY, Ahn KM, Jin DK (2006) Complications of tracheotomy in patients with mucopolysaccharidoses type II (Hunter syndrome). Int J Pediatr Otorhinolaryngol 70:1765-1769

John A, Fagondes S, Schwartz I et al (2011) Sleep abnormalities in untreated patients with mucopolysaccharidosis type VI. Am J Med Genet A 155A:1546-1551

Josephson GD, Duckworth L, Hossain J (2011) Proposed definitive grading system tool for the assessment of adenoid hyperplasia. Laryngoscope 121:187-193

Kamin W (2008) Diagnosis and management of respiratory involvement in Hunter syndrome. Acta Paediatr Suppl 97:57-60

Klug B, Bisgaard H (1996) Measurement of lung function in awake 24-year-old asthmatic children during methacholine challenge and acute asthma: a comparison of the impulse oscillation technique, the interrupter technique, and transcutaneous measurement of oxygen versus whole-body plethysmography. Pediatr Pulmonol 21:290-300

Krivit W, Pierpont ME, Ayaz K et al (1984) Bone-marrow transplantation in the Maroteaux-Lamy syndrome (mucopolysaccharidosis type VI). Biochemical and clinical status 24 months after transplantation. N Engl J Med 311:1606-1611

Leboulanger N, Louis B, Vialle R, Heron B, Fauroux B (2011) Analysis of the upper airway by the acoustic reflection method in children with mucopolysaccharidosis. Pediatr Pulmonol 46:587-594

Leighton SEJ, Papsin B, Vellodi A, Dinwiddie R, Lane R (2001) Disordered breathing during sleep in patients with mucopolysaccharidoses. Int J Pediatr Otorhinolaryngol 58:127-138

$\mathrm{Li}$ AM, Yin J, Au JT et al (2007) Standard reference for the six-minutewalk test in healthy children aged 7 to 16 years. Am J Respir Crit Care Med 176:174-180

Lin HY, Chen MR, Lin CC et al (2010) Polysomnographic characteristics in patients with mucopolysaccharidoses. Pediatr Pulmonol 45:1205-1212

Mellies U, Ragette R, Schwake C, Boehm H, Voit T, Teschler H (2003) Daytime predictors of sleep disordered breathing in children and adolescents with neuromuscular disorders. Neuromuscul Disord 13:123-128

Mokhlesi B, Tulaimat A, Faibussowitsch I et al (2007) Obesity hypoventilation syndrome: prevalence and predictors in patients with obstructive sleep apnea. Sleep Breath 11:117-124

Muenzer J (2011) Overview of the mucopolysaccharidoses. Rheumatol (Oxf) 50(Suppl 5):v4-v12

Muenzer J, Wraith JE, Beck M et al (2006) A phase II/III clinical study of enzyme replacement therapy with idursulfase in mucopolysaccharidosis II (Hunter syndrome). Genet Med 8:465-473 
Muenzer J, Wraith JE, Clarke LA (2009) Mucopolysaccharidosis I: management and treatment guidelines. Pediatrics 123:19-29

Muenzer J, Beck M, Eng CM et al (2011) Long-term, open-labeled extension study of idursulfase in the treatment of Hunter syndrome. Genet Med 13:95-101

Muhlebach MS, Wooten W, Muenzer J (2011) Respiratory manifestations in mucopolysaccharidoses. Paediatr Respir Rev 12:133-138

Murgu SD, Colt HG (2006) Tracheobronchomalacia and excessive dynamic airway collapse. Respirology 11:388-406

Myer CM III (1991) Airway obstruction in Hurler's syndrome-radiographic features. Int J Pediatr Otorhinolaryngol 22:91-96

Nagano R, Takizawa S, Hayama N et al (2007) Three-dimensional CT and histopathological findings of airway malacia in Hunter syndrome. Tokai J Exp Clin Med 32:59-61

Nashed A, Al-Saleh S, Gibbons J et al (2009) Sleep-related breathing in children with mucopolysaccharidosis. J Inherit Metab Dis 32:544-550

Okuyama T, Tanaka A, Suzuki Y et al (2010) Japan Elaprase ${ }^{\mathbb{R}}$ Treatment (JET) study: idursulfase enzyme replacement therapy in adult patients with attenuated Hunter syndrome (mucopolysaccharidosis II, MPS II). Mol Genet Metab 99:18-25

Oppenheimer BW, Goldring RM, Herberg ME et al (2007) Distal airway function in symptomatic subjects with normal spirometry following World Trade Center dust exposure. Chest 132:1275-1282

Parikh SR, Coronel M, Lee JJ, Brown SM (2006) Validation of a new grading system for endoscopic examination of adenoid hypertrophy. Otolaryngol Head Neck Surg 135:684-687

Pasker HG, Schepers R, Clement J et al (1996) Total respiratory impedance measured by means of the forced oscillation technique in subjects with and without respiratory complaints. Eur Respir J 9:131-139

Pelley CJ, Kwo J, Hess DR (2007) Tracheomalacia in an adult with respiratory failure and Morquio syndrome. Respir Care 52:278-282

Prasad VK, Kurtzberg J (2010) Transplant outcomes in mucopolysaccharidoses. Semin Hematol 47: 59-69

Ragette R, Mellies U, Schwake C, Voit T, Teschler H (2002) Patterns and predictors of sleep disordered breathing in primary myopathies. Thorax 57:724-728

Rapoport DM, Sorkin B, Garay SM, Goldring RM (1982) Reversal of "Pickwickian syndrome" by long-term use of nocturnal nasalairway pressure. New Engl J Med 307:931-933

Rovelli AM (2008) The controversial and changing role of haematopoietic cell transplantation for lysosomal storage disorders: an update. Bone Marrow Transplant 41(Suppl 2):S87-S89

Santamaria F, Andreucci MV, Parenti G et al (2007) Upper airway obstructive disease in mucopolysaccharidoses: polysomnography, computed tomography and nasal endoscopy findings. J Inherit Metab Dis 30:743-749

Semenza GL, Pyeritz RE (1988) Respiratory complications of mucopolysaccharide storage disorders. Med (Baltim) 67:209-219

Shih SL, Lee YJ, Lin SP, Sheu CY, Blickman JG (2002) Airway changes in children with mucopolysaccharidoses. Acta Radiol 43:40-43

Simmons MA, Bruce IA, Penney S, Wraith E, Rothera MP (2005) Otorhinolaryngological manifestations of the mucopolysaccharidoses. Int J Pediatr Otorhinolaryngol 69:589-595

Sims HS, Kempiners JJ (2007) Special airway concerns in patients with mucopolysaccharidoses. Respir Med 101:1779-1782

Sullivan CE, Issa FG, Berthon-Jones M, Eves L (1981) Reversal of obstructive sleep apnoea by continuous positive airway pressure applied through the nares. Lancet 1:862-865

Swiedler SJ, Beck M, Bajbouj M et al (2005) Threshold effect of urinary glycosaminoglycans and the walk test as indicators of disease progression in a survey of subjects with mucopolysaccharidosis VI (Maroteaux-Lamy syndrome). Am J Med Genet 134A:144-150

Turbeville S, Nicely H, Rizzo JD et al (2011) Clinical outcomes following hematopoietic stem cell transplantation for the treatment of mucopolysaccharidosis VI. Mol Genet Metab 102:111-115

Walker PP, Rose E, Williams JG (2003) Upper airways abnormalities and tracheal problems in Morquio's disease. Thorax 58:458-459

Walker R, Belani KG, Braunlin EA et al (2012) Anaesthesia and airway management in mucopolysaccharidosis. J Inherit Metab Dis. doi:10.1007/s10545-012-9563-1

Wang CC, Hwu WL, Lin KH (2008) Long-term follow-up of a girl with Maroteaux-Lamy syndrome after bone marrow transplantation. World J Pediatr 4:152-154

Wasserman K, Hansen JE, Sue DY, Stringer WW, Sietsema KE, Sun X-G, Whipp BJ (2012) Principles of exercise testing and interpretation, 5th edn. Lippincott Williams \& Wilkins, Philadelphia

Wold SM, Derkay CS, Darrow DH, Proud V (2010) Role of the pediatric otolaryngologist in diagnosis and management of children with mucopolysaccharidoses. Int J Pediatr Otorhinolaryngol 74:27-31

Wraith JE, Clarke LA, Beck M et al (2004) Enzyme replacement therapy for mucopolysaccharidosis I: a randomized, doubleblinded, placebo-controlled, multinational study of recombinant human a-L-iduronidase (laronidase). J Pediatr 144:581588

Yeung AH, Cowan MJ, Horn B, Rosbe KW (2009) Airway management in children with mucopolysaccharidoses. Arch Otolaryngol Head Neck Surg 135:73-79 